Heaton, Pam F., 2003. Pitch memory, labeling and disembedding in autism. Journal of Child Psychology and Psychiatry, 44 (4). pp. 543-551. Please cite the published version at http://www3.interscience.wiley.com/journal/118869780/abstract

\title{
Pitch memory, labelling and disembedding in autism
}

Pamela Heaton. Goldsmiths

A striking feature of the autistic disorder is the co-occurrence of intellectual, social and communicative deficits with enhanced abilities in specific areas (Frith, 1989). This effect is seen in its most extreme form in autistic savants, who show domain specific abilities that stand in marked contrast to their intellectual and social impairments (Miller,1989). Music is one domain within which such savant talent develops and it also appears that a preference for music can be found amongst many non-savant persons with autism (Kanner, 1943;Rimland \& Hill, 1984). In a recent questionnaire survey carried out at the Elliot House Diagnostic Centre (National Autistic Society, UK), subjects' responses indicated that for $40 \%$ of a sample of 200diagnosed individuals music was an area of special interest (Wing, personal communication).From theoretical accounts of non-social cognition in autism, predictions about specifically musical cognition may be drawn. The Executive Dysfunction account of autism has typically sought to explain diagnostic features as arising from deficits in regulating behaviour through planning, monitoring, inhibition and attention (Hughes \& Russell, 1993; Hughes, Russell, \& Robbins, 1994; Ozonoff, Pennington,\& Rogers, 1991; Prior \& Hoffman, 1990;Turner, 1999). Generally, this theory has not been invoked to explain splinter or savant skills. However, an exception is the suggestion made by Mottron, Peretz, Belleville, and Rouleau (1999) that absolute pitch ability (AP), as found in musical savants and some non-savant children with autism (Heaton, Hermelin, \& Pring, 1998), might be related to deficits in executive functions. In support of this, these authors presented findings from a case study of an autistic musical savant who showed deficits on tests of cognitive flexibility and planning. On tests of musical cognition, AP was confirmed and perception of musicalc ontours (short melodies), presented in transposed and non-transposed versions, showed no abnormalities. Weak Central Coherence theory (WCC) (Frith,1989; Happé, 1999) directly addresses the question of splinter and savant skills in autism. It proposes that autism is characterised by a cognitive style, which biases processing in favour of local features at the expense of global, context-dependent 
meaning or Gestalt (Happé, 1999) and predicts that enhanced performance will be found on tasks where good featural processing conveys an advantage. Two other theories, proposed by Plaisted (2001) and Mottronand Burack (2001), also offer some explanation forwhy superior performance on specific tasks should be seen in autism. Plaisted proposes that individuals with autism show heightened sensitivity to unique elements and reduced sensitivity to shared elements in stimuli arrays, resulting in both superior discrimination ability and difficulties in categorization and generalisation. The theory outlined by Mottron and Burack proposes reduced efficiency in domain general, higher-level cognitive mechanisms and overdevelopment of low-level modules dedicated to the processing of perceptual information. Thus both of these theories predict highly efficient processing of lowlevel perceptual information.

From theoretical accounts of non-social cognition and Burack (2001), also offer some explanation for in autism, predictions about specifically musical why superior performance on specific tasks should cognition may be drawn. The Executive Dysfunction be seen in autism. Plaisted proposes that individuals account of autism has typically sought to explain with autism show heightened sensitivity to unique diagnostic features as arising from deficits in regu-elements and reduced sensitivity to shared elements lating behaviour through planning, monitoring, in stimuli arrays, resulting in both superior disinhibition and attention (Hughes \& Russell, 1993; crimination ability and difficulties in categorisation Hughes, Russell, \& Robbins, 1994; Ozonoff, Pen-and generalisation. The theory outlined by Mottron nington, \& Rogers, 1991; Prior \& Hoffman, 1990; and Burack proposes reduced efficiency in domain Turner, 1999). Generally, this theory has not been general, higher-level cognitive mechanisms and invoked to explain splinter or savant skills. However, overdevelopment of low-level modules dedicated to an exception is the suggestion made by Mottron, the processing of perceptual information. Thus both Peretz, Belleville, and Rouleau (1999) that absolute of these theories predict highly efficient processing of pitch ability (AP), as found in musical savants and low-level perceptual information. some non-savant children with autism (Heaton, Within the musical domain, superior detail pro-Hermelin, \& Pring, 1998), might be related to deficits cessing has been observed in autism. For example, in executive functions. In support of this, these auApplebaum, Egel, Koegel, and Imhof (1979) compared three musically naive autistic 
children and three normally developing musically experienced children on their ability to sing back musical stimuli ranging from one to four tones in atonal configurations. Responses were rated for pitch, rhythm and duration and it was found that the children with autism performed as well or better than their more intelligent and musically experienced controls. Mottron, Peretz, and Menard (2000) presented adult subjects with autism and normal development with pairs of musical contours (9-tone melodies) for same/different discrimination. The contours were transposed (different pitches) and untransposed (same pitches) in contour-maintaining and contourviolating conditions.

The findings from the study revealed no group differences in levels of performance with transposed contours, indicating normal relational processing, but better discrimination of changes in contour-maintaining untransposed pairs in the autism group. However, Heaton, Pring, and Hermelin (2001) presented children with autism and age-and intelligence-matched controls with similar untransposed contourmaintaining and contour-violating 6-tone melodies, and here no group differences emerged. It seems probable that differences in findings between the two studies might reflect developmental differences (children/adults) in processing capacities and/or differences in stimuli length. In longer, untransposed melodies, information about the absolute pitches of tones becomes more accessible (Edworthy, 1985), although the detection of such differences is not reliant on absolute pitch ability. Intervallic relationships are modified in these types of melodies, so whilst pitch direction remains constant, pitch distance between adjacent tones is modified and can be detected using relational pitch processing. In one study, Heaton et al. (2001) asked children with autism and controls to judge the pitch direction of small (1-4 semitones), medium (5-8 semitones) and large (9-12 semitones) pitch intervals. Although there were no between group differences in medium and large pitch interval conditions, the children with autism showed significantly better performance with small pitch intervals than controls. Thus, enhanced on-line processing of perceptual elements or features is well established within the musical domain in autism. However, one finding suggests that in addition, other mechanisms, for example longterm pitch memory, distinguish the musical information processing of those with and without autism. In a pitch discrimination and memory task carried out by Heaton et al. (1998), groups of musically naive autistic and normally developing children were 
presented with 4 pitches and 4 word fragments for pairing with animal pictures. Recall was tested $21 / 2$ minutes and 7 days after exposure. Whilst both groups of children showed similar levels of performance pairing animal pictures and word fragments, performance with pitch stimuli was significantly higher in the autism group. Indeed, children with autism remembered more tone/picture pairs one week after initial exposure than controls did after $2 \frac{1}{2} 2$ minutes. Research indicates that in normal populations there are qualitative changes in the way that pitch information is processed through development (Trehub, Schellenberg, \& Hill, 1997). Saffran and Griepentrog (2001) presented 8-month-old infants and adults with statistical learning tasks that relied on the extraction of absolute or relative pitch cues, and found a primary reliance on absolute pitch cues in infants and relative pitch cues in adults. However, although there is a developmental decline in reliance on absolute pitch cues, they can be accessed by adults under certain conditions. For example, Levitin (1994) and Halpern (1989) found that musically untrained adults could represent the absolute pitches of well-known songs. Similarly, speakers of tone languages like Thai and Mandarin represent words at precise pitch levels (Deutsch, Hanthorn, \& Dolson, 1999). However, this capacity for absolute pitch memory is proposed to be distinct from the special ability known as absolute pitch (Levitin, 1994; Saffran \& Griepentrog, 2001), where specific labelled pitches can be identified without reference to an external standard (Baggaley, 1974; Levitin, 1994).

Studies investigating brain structure and function in populations with and without AP have confirmed the existence of differences at the neurological level. For example, Schlaug, Jancke, Huang, and Steinmetz (1995) found that musicians with AP showed stronger leftward planum temporale asymmetry than musicians and nonmusicians without this ability. Zatorre, Perry, Beckett, Westbury, and Evans (1998) also found enlarged leftward planum temporale volumes and in their study this correlated with performance on a pitch-naming task. In this latter investigation positron emission tomography was also used to measure cerebral blood flow during performance of pitch and interval naming tasks in AP possessors and nonpossessors. On pitch-naming tasks activation of auditory cortical areas was found in both groups, but unlike non-possessors, AP subjects also showed activation of the left posterior dorsolateral frontal cortex. However, activation of this area was seen in both groups on the interval-naming task. Pitch interval names are acquired during the 
course of musical training and their identification does not require stable representations of individual tones as they are characterised by pitch distances between tones. On the interval-naming task AP non-possessors also showed changes in $\mathrm{CBF}$ in the right inferior frontal region, suggesting the maintenance of pitch information in auditory short-term memory. AP possessors did not show this pattern of activation and Zatorre et al. suggest that AP possessors may not need to access working memory for interval judgements because they can classify individual tones within intervals by name. Thus these authors suggest that AP may reflect an ability to retrieve an arbitrary association between a stimulus attribute (a pitch) and a verbal label. However, they also cite evidence showing that interference of verbal rehearsal does not disrupt note naming in AP possessors, thereby suggesting that for them, other sensory codes for pitches are available.

Absolute pitch ability is extremely rare in normal populations, being found in only 1 in 10,000 individuals (Tacheuchi \& Hulse, 1993). However, such ability has been reported in all the musical savants in the extant literature (Miller, 1989; Mottron et al., 1999). Miller's (1989) description of a young musical savant who clearly demonstrated AP ability prior to the acquisition of note names supports Zatorre et al.'s proposal that pitches can be mediated by non-verbal codes. Possible implications of such an ability in individuals with the complex patterns of social, intellectual and often sensory deficits seen in savants are difficult to quantify, although Miller (1989) has provided a convincing account of how AP might facilitate musical development in these individuals. Certainly the possession of AP has been shown to convey an advantage that goes beyond the ability to remember and name individual tones. For example, musical savants are frequently able to name or reproduce tones embedded in complex note clusters. This was first reported in the mid-nineteenth century in a description of the musical savant Thomas Wiggins (reported in Southall, 1983) and more recently, Miller (1989) has confirmed this experimentally. In his study, musical savants and normal controls with AP showed very similar high levels of chord reproduction despite wide variations in age, intelligence and musical training. In contrast, significantly poorer performance was seen in a control group of normal young adults with at least 8 years of piano tuition and relative pitch. It thus appears, as Miller suggests, that AP ability has important 
consequences for some aspects of musical cognition, in this case chord disembedding.

In neural network accounts of musical perception, chords occupy a hierarchically higher position than the individual notes of which they are comprised (for example, Bharucha, 1991). In some types of chords the relationship between tones and overtones creates powerful 'fusion' effects (for discussion, see Cross, 1997); for example, tonic triads include the third and fifth degrees of the scale and these are represented in the harmonics of the tone that provides the root of the chord. Thus, whilst comprising three individual notes, they are powerfully coalescing musical Gestalts that function primarily to provide harmonic information (Krumhansl, Bharucha, \& Kessler, 1982). However, individuals with AP both with and without autism are able to unpack these Gestalt configurations in order to access individual component tones (Miller, 1989). Interestingly, the ability to disembed individual elements from within visual Gestalts has been noted in autistic individuals both with and without savant skills (Pring, Hermelin, \& Heavey, 1995; Shah \& Frith, 1983, 1993; Happé, 1996). Thus the question to be asked in the present investigation is whether exceptional chord disembedding might be seen in non-savant individuals with autism.

The hypothesis for the following experiments is that children with autism will be able to decompose musical chords in order to identify individual component tones. The rationale for the experiments is that AP ability and exceptional chord disembedding have been noted in musical savants (Miller, 1989); the savant syndrome is closely associated with autism (Rimland \& Hill, 1984; Young, 1995); individuals with autism show a predisposition towards featural processing (Happe', 1999) and possess good pitch discrimination (Heaton et al., 1998; Mottron et al., 2000), pitch memory and labelling (Heaton et al., 1998).

\section{Experiment 1: Investigating pitch memory and labelling}

\section{Method}

Participants. All participants were attending a specialist provision for children with autistic spectrum disorders. For entry to this school, diagnosis according to standard 
clinical criteria is necessary. Fourteen children aged between 7 years, 9 months and 15 years (Mean: 10 years, 9 months) participated in experiments 1 and 2 . Their scores on the Raven's Matrices ranged between 87 and 147 (Mean 108) and their scores on the Peabody Picture Vocabulary Test ranged between 56 and 126 (Mean 93). Thirteen of these children and two additional children participated in experiment 3. In this study children were aged between 7 years, 3 months and 14 years, 9 months (Mean 10 years). Scores on the Raven's Matrices ranged between 99 and 147 (Mean 107) and scores on the Peabody Picture Vocabulary ranged between 56 and 126 (Mean 92). Two of the children with autism had verbal IQ scores of 56 and the individual scores for the rest of the sample fell approximately within the normal range. As the experimental tasks included both verbal and non-verbal components, two control groups were included. The children in the two control groups were matched to the autistic children on an individual basis for chronological age, gender, and either performance on the Peabody Picture Vocabulary Test (Group 2) or the Raven's Matrices (Group 3). Two of the children in the verbal IQ-matched control group attended a school for children with moderate learning difficulties and the remaining children attended mainstream schools.

Musical experience. In order to control for any potential effects of music/aural training in the studies, children and teachers were questioned about music lessons and those who had undergone formal musical training, in the form of extended periods of individual instrumental or singing lessons, were excluded.

Stimuli. The musical tones used in the experiment were D4, F\#4, A4 and D5 and they were presented on a Casiotone 202 electronic keyboard (acoustic piano setting) by the experimenter. The keyboard was out of the child's view. Each of the tones was presented in conjunction with a picture of a different animal. The pictures were taken from the Snodgrass and Vanderwart (1980) Picture Norms Set and represented a mouse, a camel, an owl and a rabbit.

Procedure. The procedure was adapted from that used in an earlier study into pitch memory (Heaton et al., 1998). Four notes were presented in a quasi-randomised order over 48 trials. The 48 trials were randomised in such a way that the child heard each particular tone and was shown its associated picture 12 times during the total procedure, that is, four times in each of the following main blocks. For the first block 
of 16 training trials, the four animal pictures were placed together in front of the child. The child was asked to name each of the animal pictures and was told after the naming response that this animal had a favourite note. The tone was then sounded while the experimenter pointed to the appropriate animal picture. During the second block of 12 trials, the animal pictures were removed, thus focusing concentration on the auditory stimuli alone. Before each tone was sounded, the experimenter told the child 'this is the note that the (owl, mouse, camel or rabbit) likes best'. Following this, the procedure used for the first 16 trials was repeated in the last 16-trial block. This part of the procedure served to establish associations between a tone and its label.

Pitch identification. After the familiarisation session, the child was engaged in conversation about an unrelated topic for a period of $21 / 2$ minutes. The four animal pictures were then placed together before the child. The previously presented tones were sounded over 16 trials in a quasi-randomised order, so that every tone was heard four times. The child was asked to respond to each sounded tone by pointing to the animal 'that liked this note best', and their responses were recorded.

\section{Results}

The means and standard deviations for correct identification of tone/animal pairs are shown in Table 1.

The data was subjected to Analysis of Variance and revealed a highly significant effect of group $(F(2 ; 39)=7.79, p<.001)$, with the children with autism performing at a significantly higher level than those in the two matched control groups, for whom performance levels were very similar. These findings will be considered in the discussion below.

Table 1: Means and standard deviations for the correct identification of tonelanimal pairs

\begin{tabular}{|l|l|l|}
\hline & Mean & SD \\
\hline Autism group & 11.21 & 4.67 \\
\hline VIQ matched controls & 6.50 & 3.06 \\
\hline Non-verbal matched controls & 6.21 & 3.35 \\
\hline \multicolumn{2}{|l}{} \\
\hline \multicolumn{2}{|l}{ Maximum score $=16}$. & \\
\hline
\end{tabular}




\section{Experiment 2: Disembedding familiar labelled tones from within musical chords}

\section{Method}

Stimuli. The stimuli were 4 alternative versions of a D major tonic triad each of which were presented four times. The chords comprised three of the four tones (D3, F\#3, A3 and D4) to which the subjects had been familiarised, together with their associated animal pictures in Experiment 1. The 16 chords were presented, in randomised order, on a Casiotone 202 electronic keyboard (acoustic piano setting) by the experimenter. The keyboard was out of the child's view.

Procedure. In Experiment 1, participants had been exposed to tone/animal pairs and after three familiarisation blocks correct responses had been recorded (Table 1). Experiment 2 began immediately after this and began with the presentation of a further familiarisation block. The children remained seated at the table on which the four animal pictures were arranged and were again exposed to each of the animal/tone pairings over 16 trials. After this familiarisation block was completed the children were told that they were going to listen to groups of three animal notes. The experimenter gave the following instructions: 'I am going to play three of the animal notes together, and I am going to leave one out. Can you point to the animal whose note is missing?' The subjects' responses were recorded.

\section{Results}

The means and standard deviations for correct identification of the tone/animal missing from chords are shown in Table 2.

A one-way Analysis of Variance was carried out on the data and revealed a significant effect of group $(F(2 ; 39)=3.97, p<.027)$, with children with autism performing at a higher level than controls.

The findings from this experiment suggest that children with autism are better able than controls to use pre-exposed and labelled pitch representations in an analytical task that requires the mental segmentation of musical chords. The question to be asked in the following study is whether this ability will persist when pre-exposure and 
cueing are reduced. Thus, when not cued towards individual tones, perception of the chord's Gestalt qualities might reduce the autistic children's tendency towards featural processing.

Table 2: Means and standard deviations for the correct identification of tonelanimal pairs excluded from musical chords

\begin{tabular}{|l|l|l|}
\hline & Mean & SD \\
\hline Autism group & 7.50 & 4.83 \\
\hline VIQ matched controls & 4.28 & 3.02 \\
\hline Non-verbal matched controls & 3.71 & 3.40 \\
\hline \multicolumn{2}{|l}{} \\
\hline
\end{tabular}

\section{Experiment 3: Disembedding unlabelled tones from within musical}

\section{chords}

\section{Method}

Stimuli. Twenty-four chords (12 major and 12 minor) were used in each of the experimental conditions and were randomised across modality (major/minor) and across keys. As in experiment 2, the chords were tonic triads comprising the first, third and fifth degrees of the scales of the given keys. Comparison notes were the first, third or fifth degrees of the scales of the given keys (correct) or the second, fourth or sixth degrees of the scales of the given keys (incorrect). Chords were presented on a Casiotone 202 electronic keyboard (acoustic piano setting) by the experimenter.

Procedure. Simultaneous training phase: Children were shown a picture of an elephant that was then placed face down. They were then shown real or modified segments of the picture and were asked 'is this a piece of the elephant picture you just saw?' Sequential training phase: Here presentation of the whole picture was preceded by exposure to the three correct segments. There were 24 trials in each of these phases and feedback was given after each incorrect response.

Simultaneous experimental phase: Children were told that the task was to be repeated using music and were instructed to listen to chords followed by individual tones. They were required to state whether or not the individual tone was part of the 
chord that preceded it. There were 24 trials and feedback was given on the first four only. Sequential experimental phase: Here, the sounding out, in ascending order, of the individual notes that comprised the chord preceded presentation of chords. Again the children were required to state whether or not the individual tone was part of the chord that preceded it. There were 24 trials and feedback was given on the first four only. Presentation of the two experimental conditions (simultaneous and sequential) was randomised within groups. Correct and incorrect responses were recorded by the experimenter.

\section{Results}

The means and standard deviations for correct comparison of target tones with chords are shown in Table 3.

Table 3: Means and standard deviations for the subject's correct comparison of target tones with simultaneous and sequentially presented consonant chords

\begin{tabular}{|l|c|c|c|c|}
\hline & \multicolumn{2}{|c|}{ Simultaneous condition } & \multicolumn{2}{c|}{ Sequential condition } \\
\hline & Mean & SD & Mean & SD \\
\hline Autism group & 15.53 & 3.56 & 16.13 & 5.09 \\
\hline VIQ matched controls & 13.67 & 2.02 & 14.60 & 3.46 \\
\hline Non-verbal matched controls & 14.07 & 2.19 & 14.73 & 2.60 \\
\hline & \multicolumn{4}{|l}{} \\
Maximum score $=24$.
\end{tabular}

An Analysis of Variance with condition (simultaneous/sequential) as the within group factor and group as the between group factor was carried out on the data. The analysis failed to reveal a significant effect of group $(F(2 ; 42)=1$. 46, n.s. $)$, condition $(F(1)=2.46$, n.s. $)$, or group $\times$ condition $(F(2)=.05$, n.s. $)$. As these findings failed to show superior dis-embedding ability in the autism group, further analyses were carried out.

In order to determine chance levels of performance within groups, binomial tests were carried out on the data. It was found that performance was above chance level for $60 \%$ of individuals in group 1 (autism), 47\% in group 2 (VIQ-matched controls) and $53 \%$ in group 3 (Non-VIQ-matched controls) $(p<.05)$.

In a second analysis, scores for correctly identified target tones that were the same as those embedded in the chords were compared to correctly identified tones that 
were different to those embedded in the chords. The means and standard deviations for these same/different identifications are shown in Table 4.

An analysis of variance was carried out with correct identification (same/different) as the within subjects factor and diagnosis (autism/controls) as the between subjects factor. There was no significant effect of group $(F(2.42)=1.64$, n.s. $)$, but there was a trend towards statistical significance for condition $(F(1)=1.64, p<.06)$, indicating better identification of different targets. There was no significant effect of group condition.

\section{Discussion}

The findings from these experiments provide only partial support for the experimental hypothesis in that chord disembedding superiority in autism appears to be highly dependent on the type of experimental paradigm used. However, the findings clearly show that there are qualitative differences in the way that autistic and normally developing children represent and process pitch information. In experiment 1 the children with autism showed significantly better retrieval of individual labelled tones than controls and in experiment 2 they showed better disembedding of these preexposed tones from musical chords. In experiment 3, where tones were not preexposed and retrieval labels were not provided, no group differences emerged and the autism group, like controls, succumbed to the Gestalt qualities of the chords.

Table 4: Means and standard deviations for subject's correct identification of same (embedded) and different (not embedded) target tones

\begin{tabular}{|l|c|c|c|c|}
\hline & \multicolumn{2}{|c|}{ Same target } & \multicolumn{2}{c|}{ Different target } \\
\hline & Mean & SD & Mean & SD \\
\hline Autism group & 15.26 & 4.25 & 16.40 & 5.15 \\
\hline VIQ matched controls & 12.99 & 4.13 & 14.60 & 3.48 \\
\hline Non-verbal matched controls & 13.46 & 3.90 & 15.33 & 3.69 \\
\hline Maximum score = 24. & \multicolumn{4}{|l}{} \\
\hline
\end{tabular}

In experiment 1 task performance was dependent on pitch memory. It was suggested in the introduction that AP ability may not necessarily depend on learned verbal codes, and both neurological findings (Zatorre et al., 1998) and reports of AP ability prior to the acquisition of verbal labels (Miller, 1989) provide support for this suggestion. Experimental evidence suggests that individuals with AP do not 
remember sounds of pitches, but instead identify tones and remember pitch names (Tacheuchi \& Hulse, 1993). The participants in the present investigation had not undergone musical training and did not possess pitch labels. However, the paradigm used in this study provided retrieval cues, thereby allowing individuals without AP as currently defined (Baggaley, 1974; Levitin, 1994) to demonstrate the existence of stable representations for specific musical tones.

In experiment 2 the experimental method focused attention on the component tones within the chords and made retrieval easier by providing tone labels. However, normally developing controls were still unable to access the tones within the chords and significant group differences emerged. Task success in this experiment depended upon three cognitive operations. First, representations for pitch/animal pairs had to be formed and stored in long-term memory. Secondly, the presented chord had to be segmented into its component parts in order that the third cognitive operation, identifying the fourth missing component, could be carried out. Thus task performance depended on associate learning and both long-and short-term memory capacities. In a recent investigation into memory functions in autism (Minshew \& Goldstein, 2001), associate-learning and short-term memory were found to be intact. In addition, difficulties on delayed recall tasks tended to emerge when test materials increased in semantic complexity, thus suggesting that delayed recall may not in itself be impaired. Whilst it thus becomes evident that cognitive mechanisms essential to good performance on the reported tasks are unimpaired in autism, superior long-term memory encoding and retrieval of pitch information in the autism group remain unexplained. The pitch encoding and retrieval difficulties experienced by normally developing controls in experiments 1 and 2 might be considered with reference to data from non-AP possessors reported by Zattorre et al. (1998). Tones presented for associate learning (as in experiment 1), if rehearsed in short-term auditory memory, are highly susceptible to interference from subsequently presented tones. Sequential presentation of chords would have a similarly disrupting effect. However, individuals with AP who appear to be less reliant on auditory working memory are correspondingly less susceptible to such interference effects. Taken together, the findings from experiments 1 and 2 show that in autism pitch representations are more accessible and stable than is normally the case so that task performance more nearly resembles that of individuals with AP (Miller, 1989). 
In experiment 3, when subjects were presented with tonic triads in simultaneous and sequential conditions for disembedding, no group differences emerged. Although exceptional chord disembedding is found in individuals with savant talents (Miller, 1989) and musical splinter skills (Heaton, 1998; Heaton, Pring, \& Hermelin, 1999), and good visual disembedding has been well documented in autism (Shah \& Frith, 1983, 1993), such enhanced abilities were not seen in experiment 3. This task proved to be fairly difficult, although more than half of the participants were able to perform at levels that were significantly above chance. However, the same/different analysis showed that all subjects tended to experience greater difficulty identifying same target tones (embedded) than different target tones (not embedded). It may then be the case that any good performance observed did not rest on disembedding ability, but instead reflected a capacity to identify different notes that sounded dissonant or harmonically incongruent in comparison to the previously heard chord.

In Shah and Frith's (1993) study children with autism and controls were presented with segmented and unsegmented block designs for reconstruction. Whilst the good performance of the children with autism was not facilitated by pre-segmentation of designs, this was the case for the control children. Experiment 3 included a condition (sequential) in which component tones were sounded out prior to presentation of chords and comparison target tones; however, performance was no better here than on the simultaneous condition where no pre-segmentation of chords had occurred. In many visual disembedding tasks (i.e., Shah \& Frith, 1993) parts and wholes remain perceptually available during task performance and this contrasts with the current tasks in which stimuli were auditory and sequential in nature. In the first experiment presented here, $71 \%$ of the children with autism were able to form stable representations for tone/animal pairs and for $43 \%$ these could be retrieved from chords in experiment 2. Although the control children performed at low levels on experiments 1 and 2, where task performance was dependent on the ability to represent and retrieve pitch/animal pairs, their performance on experiment 3, where memory demands were reduced, improved and equalled that of the children with autism. Thus, whilst the findings presented here do not provide evidence for generally enhanced auditory disembedding ability in autism, they do show that such abilities can be sustained under conditions in which heavy demands are made on 
long-term pitch memory. The findings of superior pitch encoding and recall in autism will now be considered within the context of our current understanding of the development of pitch processing mechanisms in normal populations.

It has long been held that there is a sensitive period for the acquisition of AP. In support of this are studies showing correlations between the early onset of musical training and the probability of possessing $\mathrm{AP}$, and higher success rates for younger than older children on AP training programmes (see Tacheuchi \& Hulse, 1993, for review). However, evidence for AP in neonates has led Saffran and Griepentrog (2001) to outline an alternative unlearning hypothesis that offers a persuasive account of early pitch development across music and language domains. At the earliest stages of development infant attention is focused primarily on contour information (for experimental evidence see Trehub, Shellenberg, \& Hill, 1997); absolute pitch cues are less salient but are accessed when contour information is unavailable, as was the case in Saffran and Griepentrog's statistical learning task. This early ability to represent contour indicates that 'rough-grained' relative pitch (RP) processing mechanisms are in evidence. However, many distinct melodies share similar contours and melody discrimination and memory requires finer-grained levels of analysis. The development of the ability to represent pitch distance allows the infant to map precise intervals between tones and in combination with pitch direction provides for more detailed melody representations. In music, pitch is organised in discrete intervals along octaves and these form the scales of the different musical keys. Thus, the development of relative pitch processing mechanisms allows the organisation of pitch information and the subsequent representation and processing of higher-level harmonic information. An inability to develop relative pitch processing would place serious constraints on musical perception and cognition, for example, disallowing recognition of melodies in transposition. As previously suggested, adults with AP are frequently reported as having experienced increased exposure to music early in development and it appears that this has served to stabilise AP representations which then coexist alongside the more mature RP processing abilities (Trehub et al., 1997).

The autistic musical savant with AP described by Mottron et al. (1999) showed deficits on tests of cognitive flexibility and these authors suggest that AP may 
stabilise in musical savants because such a deficit might create a predisposition towards the repetitive and inflexible processing of information within domains of interest. Thus, neurological abnormalities expressed at behavioural levels are proposed to account for AP ability in savants. Of relevance here are reports of atypical auditory information processing in autism. For example, many children show extreme sensitivity to a variety of environmental sounds (Bauman, 1999) and lateralisa tion abnormalities at the auditory periphery have been noted (Khalfa et al., 2001). Mu“ller et al. (1999) used positron emission tomography to investigate patterns of activation in response to auditory information and found atypical functional asymmetry for both language and pitch stimuli in their autism group. In response to pitch stimuli, the autism group, unlike controls, showed activation of the left anterior cingulate gyrus. They also showed reduced bilateral superior temporal and cerebellar activations in comparison to controls.

It is noteworthy that developmentally atypical patterns of auditory attending are frequently reported in autism. For example, both clinical (Clancy \& McBride, 1969; Kanner, 1943; Prior \& Gajzago, 1974; Rutter, 1968) and experimental (Klin, 1991) evidence suggests that young autistic children often fail to show a preference for speech above other types of auditory stimuli. Of particular relevance to the current investigation is Blackstock's (1978) finding of an autism-specific preference for musical over verbal stimuli. Difficulties in processing stimuli with high levels of semantic complexity, for example language (Minshew \& Goldstein, 2001), might influence the development of such a preference. It may then be the case that even in the absence of a domain-specific interest, as seen in musical savants, the reduced salience of language, if operating at early stages in development, creates conditions in which other types of auditory information become more important and are more intensively processed.

Previously cited evidence strongly suggests that the acquisition of AP ability is constrained developmentally; however, sensitive periods for the development of specific processing mechanisms cannot be assumed to follow a normal developmental trajectory in those with neurodevelopmental disorders. For example, individuals with Williams syndrome have been found to be able to acquire note names in adulthood, whilst in normal populations such potential abilities are lost by 
approximately 6 years (Lenhoff, Perales, \& Hickok, 2001). The findings from the experiments described here strongly suggest that in autism, as in Williams syndrome, the potential to acquire or stabilise AP ability has a longer duration than seen in normal development.

A major strength of the theoretical accounts of autistic cognition outlined in the introduction is that they attempt to explain enhanced performance on specific tasks. However, theories proposing enhanced on-line processing of perceptual information fail to account for the findings presented here, as enhanced task performance (experiments 1 and 2) is best explained by superior recall of pitch information and intact paired-associate learning and working memory. In experiment 3 , where enhanced perceptual discrimination abilities, as proposed by Mottron and Burack (2001) and Plaisted (2001), might be expected to advantage autistic subjects, no group differences emerged.

Happé's (1999) suggestion that autistic cognition is characterised by a tendency towards featural processing and exemplar encoding provides the clearest link between autistic cognition and what is known about the acquisition or stabilisation of AP ability in normal populations. In the AP training technique developed by Oura and Eguchi (1981), young children's attention was focused on individual tones within three-note chords and sequential musical material was avoided. Thus detail-focused processing of musical material, within a specified developmental time frame, was promoted and led to the stabilisation of AP. It is thus proposed that a cognitive bias towards featural processing as outlined by Happé (1999) is an important factor in predisposing AP in autism. It may also be the case that the reduced salience of language and the weaker operation of developmental constraints against AP stabilisation are important contributory factors. However, whilst behavioural data allows important insights into pitch processing in autism, neurological investigations might well provide the clearest evidence for similarities and differences between normally developing individuals with AP and those with autism that show exceptional pitch labelling and memory. Such investigations are currently being planned.

\section{Acknowledgements}




\section{Thanks to Ati Hermelin and Linda Pring for ongoing help and support, to Uta Frith,}

Francesca Happé and Greg Wallace for helpful discussion and comments on the manuscript, and to all the participants and their teachers for their kind cooperation in these studies.

\section{References}

Applebaum, E., Egel, A.L., Koegel, R.L., \& Imhoff, B. (1979). Measuring musical abilities of autistic children. Journal of Autism and Developmental Disorders, 9, 279-285.

Baggaley, J. (1974). Measurement of absolute pitch: A confused field. Psychology of Music, 2, 11-17.

Bauman, M.L. (1999). Autism: Clinical features and neurobiological observations. In H. Tager-Flusberg (Ed.), Neurodevelopmental Disorders. Cambridge, MA: MIT Press.

Bharucha, J.J. (1991). Pitch, harmony and neural nets: A psychological perspective. In P. Todd \& D.G. Loy (Eds.), Music and connectionism. Cambridge, MA: MIT Press.

Blackstock, E.G. (1978). Cerebral asymmetry and the development of early infantile autism. Journal of Autism and Childhood Schizophrenia, 8, 339-353.

Clancy, H., \& McBride, G. (1969). The autistic process and its treatment. Journal of Child Psychology and Psychiatry, 10, 233-244.

Cross, I. (1997). Pitch schemata. In I. Deliege \& J. Sloboda (Eds.), Perception and Cognition of Music. Hove: Psychology Press.

Deutsch, D., Hanthorn, T., \& Dolson, M. (1999, November). Tone language speakers possess absolute pitch. Paper presented at the 138th meeting of the Acoustical Society of America, Columbus, Ohio.

Edworthy, J. (1985). Interval and contour in melody processing. Music Perception, 2, 375-388.

Frith, U. (1989). Autism: Explaining the enigma. Oxford: Blackwell.

Halpern, A.R. (1989). Memory for the absolute pitch of familiar songs. Memory and Cognition, 17, 572-581.

Happe', F.G.E. (1996). Studying weak central coherence at low levels: Children with autism do not succumb to visual illusions. A research note. Journal of Child Psychology and Psychiatry, 37, 873-877.

Happe', F.G.E. (1999). Autism: Cognitive deficit or cognitive style? Trends in Cognitive Sciences, 3, $216-222$.

Heaton, P. (1998). Musical cognition in children with autism. PhD thesis, Goldsmiths College, University of London.

Heaton, P., Hermelin, B., \& Pring, L. (1998). Autism and pitch processing: A precursor for savant musical ability? Music Perception, 154, 291-305.

Heaton, P., Pring, L., \& Hermelin, B. (1999). A pseudo-savant: A case of exceptional musical splinter skills.

Neurocase, 5, 503-509.

Heaton, P., Pring, L., \& Hermelin, B. (2001) Musical processing in high functioning children with autism. The biological foundations of music. Annals of the New York Academy of Sciences, 930, New York.

Hughes, C., \& Russell, J. (1993). Autistic children's difficulty with mental disengagement from an object: Its implications for theories of autism. Developmental Psychology, 29, 498-510.

Hughes, C., Russell, J., \& Robbins, T.W. (1994). Evidence for executive dysfunction in autism. Neuropsychologia, 32, 477-492.

Kanner, L. (1943). Autistic disturbances of affective contact. Nervous Child, 2, 217-250.

Khalfa, S., Bruneau, B., Roge', B., Georgieff, N., Veuillet, E., Adrien, J.L., Barthe'le'my, C., \& Collet, L. (2001). Peripheral auditory asymmetry in infantile autism. European Journal of Neuroscience, 13, 628-632.

Klin, A. (1991). Young autistic children's listening preferences in regard to speech: A possible characterisation of the symptom of social withdrawal. Journal of Autism and Developmental Disorders, 21, 29-42.

Krummhansl, C.L., Bharucha, J.J., \& Kessler, E.J. (1982). Perceived harmonic structures of chords in three related keys. Journal of Experimental Psychology: Human Perception and Performance, 8, 24-36. 
Lenhoff, H.M., Perales, O., \& Hickok, G.S. (2001). Preservation of a normally transient critical period in a cognitively impaired population: Window of opportunity for acquiring absolute pitch in Williams syndrome. In C.A. Shaw \& J.C. McEachern (Eds.), Toward a theory of neuroplasticity. Philadelphia: Psychology Press.

Levitin, D.J. (1994). Absolute memory for musical pitch: Evidence from the production of learned melodies. Perception and Psychophysics, 56, 414-423.

Miller, L. (1989). Musical savants: Exceptional skills in the mentally retarded. Hillsdale, NJ: Erlbaum.

Minshew, N.J., \& Goldstein, G. (2001). The pattern of intact and impaired memory functions in autism. Journal of Child Psychology and Psychiatry, 42, 1095-1101.

Mottron, L., \& Burack, J.A. (2001). Enhanced perceptual functioning in the development of autism. In J.A. Burack, T. Charman, N. Yirmiya, \& P.R. Zelazoo (Eds.), The development of autism (pp. 131-148). Mahwah, NJ: Lawrence Erlbaum Associates.

Mottron, L., Peretz, I., Belleville, S., \& Rouleau, N. (1999). Absolute pitch in autism: A case study. Neurocase, 5, 485-501.

Mottron, L., Peretz, I., \& Menard, E. (2000). Local and global processing of music in high-functioning persons with autism: Beyond central coherence? Journal of Child Psychology and Psychiatry, 41, 1057-1065.

Müller, R.A., Behen, M.E., Rothermel, R.D., Chugani, D.C., Muzik, O., Mangner, T.J., \& Chugani, H.T. (1999). Brain mapping of language and auditory perception in high-functioning autistic adults: A PET study. Journal of Autism and Developmental Disorders, 29, 19-28.

Oura, Y., \& Eguchi, K. (1981). Is absolute pitch innate or acquired? Paper presented at the Colloquium of the XV1th International Music Festival, Brno, Czechoslovakia.

Ozonoff, S., Pennington, B., \& Rogers, S. (1991). Executive function deficits in high-functioning autistic children: Relationship to theory of mind. Journal of Child Psychology and Psychiatry, 32, 1081-1106.

Plaisted, K.C. (2001). Reduced generalization in autism: An alternative to weak central coherence. In J.A. Burack, T. Charman, N. Yirmiya, \& P.R. Zelazo (Eds.), The development of autism (pp. 149-169). Mahwah, NJ: Lawrence Erlbaum Associates.

Prior, M., \& Gajzago, C. (1974, August 3). Recognition of early signs of autism. Medical Journal of Australia.

Prior, M., \& Hoffman, W. (1990). Neuropsychological testing of autistic children through an exploration with frontal lobe tests. Journal of Autism and Developmental Disorders, 20, 581-590.

Pring, L., Hermelin, B., \& Heavey, L. (1995). Savants, segments, art and autism. Journal of Child Psychology and Psychiatry, 36, 1065-1076.

Raven, J.C., Court, J.H., \& Raven, J. (1988). Standard progressive matrices. London: H.K. Lewis and Co.

Rimland, B., \& Hill, A. (1984). Idiots savants. In J. Wortes (Ed.), Mental retardation and developmental disabilities (vol. 13, pp. 155-169). New York: Plenum Press.

Rutter, M. (1968). Concepts of autism: A review of research. Journal of Child Psychology and Psychiatry, 9, 1-25.

Saffran, J.R., \& Griepentrog, G.J. (2001). Absolute pitch in infant auditory learning: Evidence for developmental reorganization. Developmental Psychology, 37, 74-85.

Shah, A., \& Frith, U. (1983). An islet of ability in autistic children: A research note. Journal of Child Psychology and Psychiatry, 24, 613-620.

Shah, A., \& Frith, U. (1993). Why do autistic individuals show superior performance on the block design test? Journal of Child Psychology and Psychiatry, 34, 1351-1364.

Schlaug, G., Jancke, L., Huang, Y., \& Steinmetz, H. (1995). In vivo evidence of structural brain asymmetry in musicians. Science, 267, 699-701.

Snodgrass, G., \& Vanderwart, M. (1980). A standardised set of 260 pictures: Norms for name agreement, image agreement, familiarity and visual complexity. Journal of Experimental Psychology: Human Learning and Memory, 6, 174-215.

Southall, G. (1983). The continuing enslavement of blind Tom, the pianist composer, (1868-1887). Minneapolis, $\mathrm{MN}$ : Challenge Productions.

Takeuchi, A.H., \& Hulse, S.H. (1993). Absolute pitch. Psychological Bulletin, 113, 345-361.

Trehub, S., Schellenberg, E., \& Hill, D. (1997). The origins of music perception and cognition: A developmental perspective. In I. Deliege and J. Sloboda (Eds.), Perception and cognition of music (pp. 103- 123). Hove: Psychology Press.

Turner, M. (1999). Generating novel ideas: Fluency performance in high-functioning and learning disabled individuals with autism. Journal of Child Psychology and Psychiatry, 40, 189-201. 
Young, R. (1995). Savant syndrome: Processes underlying extraordinary abilities. Unpublished PhD Dissertation, University of Adelaide, South Australia.

Zatorre, R.J., Perry, D.W., Beckett, C.A., Westbury, C.F., \& Evans, A.C. (1998). Functional anatomy of musical processing in listeners with absolute pitch and relative pitch. Proceedings of the National Academy of Sciences, USA, 95, 3172-3177. 